\title{
Climate change presents increased potential for very large fires in the contiguous United States
}

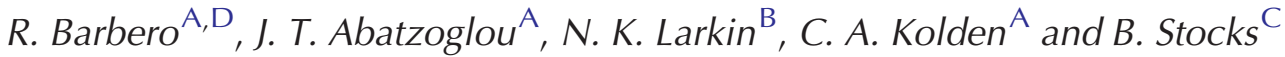 \\ A Department of Geography, University of Idaho, 875 Perimeter Drive MS3021, Moscow, \\ ID 83844-3021, USA. \\ B Pacific Wildland Fire Sciences Laboratory, US Forest Service, 400 North 34th Street, Suite 201, \\ Seattle, WA 98103, USA. \\ ${ }^{C}$ Canadian Forest Service, Great Lakes Forestry Centre, 1219 Queen Street East, Sault Ste. Marie, \\ ON P6A 2E5, Canada. \\ DCorresponding author. Email: renaudb@uidaho.edu
}

\begin{abstract}
Very large fires (VLFs) have important implications for communities, ecosystems, air quality and fire suppression expenditures. VLFs over the contiguous US have been strongly linked with meteorological and climatological variability. Building on prior modelling of VLFs $(>5000 \mathrm{ha})$, an ensemble of 17 global climate models were statistically downscaled over the US for climate experiments covering the historic and mid-21st-century periods to estimate potential changes in VLF occurrence arising from anthropogenic climate change. Increased VLF potential was projected across most historically fire-prone regions, with the largest absolute increase in the intermountain West and Northern California. Complementary to modelled increases in VLF potential were changes in the seasonality of atmospheric conditions conducive to VLFs, including an earlier onset across the southern US and more symmetric seasonal extension in the northern regions. These projections provide insights into regional and seasonal distribution of VLF potential under a changing climate, and serve as a basis for future strategic and tactical fire management options.
\end{abstract}

Additional keywords: climate-fire models, climate variability, fire risks, megafires.

Received 9 January 2015, accepted 4 June 2015, published online 16 July 2015

\section{Introduction}

Very large fires (VLFs; often defined as the top 5 or $10 \%$ of the largest fires) account for a majority of burned area in many regions of the US (e.g. Strauss et al. 1989), increasingly threaten and affect homes and communities, have unique ecological effects on ecosystems, contribute to widespread degradation in air quality (e.g. Schultz et al. 2008) and lead to numerous indirect effects including those on human health (e.g. Johnston et al. 2012) and water quality (e.g. Rhoades et al. 2011). An increase in the number of VLFs has been observed in recent decades across the US (Dennison et al. 2014). Although difficult to apportion causation, both the legacy of fire suppression allowing for increased fuel accumulation (Marlon et al. 2012) and a more favourable climate (Barbero et al. 2014a) have likely enabled more frequent VLFs. According to the National Interagency Fire Center, direct federal expenditures on fire suppression in the US have more than doubled in recent decades, exceeding US\$1 billion per year since the year 2000, the vast majority of which is spent on large incidents. Collectively, such changes have taxed fire suppression resources and prompted the need for fire agencies to reallocate funding from a broader set of land management objectives to specifically fighting fire.

Most VLFs in the US occur coincident with favourable fuel and fire spread conditions facilitated by antecedent climate and current extreme fire weather conditions respectively (e.g. Riley et al. 2013; Stavros et al. 2014a; Barbero et al. 2014b). These relationships are similar to the broader body of climate-fire studies linking interannual climate variability and spatially aggregated burned area (e.g. Westerling et al. 2003; Littell et al. 2009). Observed changes in climate may have already influenced wildfire potential over parts of the globe (e.g. Stocks et al. 1998; Gillett et al. 2004; Westerling et al. 2006), and projected changes in climate over the next century are hypothesised to significantly alter global wildfire regimes (e.g. Flannigan et al. 2009), including across parts of the US, via changes in fire danger (e.g. Brown et al. 2004; Abatzoglou and Kolden 2011; Liu et al. 2012), moisture deficits (Westerling et al. 2011a; Westerling et al. 2011b) and vegetation composition (Bradley 2009). Prior studies reported increased annual (sometimes monthly) burned area for parts of the US with climate change (e.g. Spracklen et al. 2009; Westerling et al. 2011a, 2011b; Yue et al. 2013); however, such studies have been limited to the western US and did not provide insights on future VLF occurrence (see Table 1). In the only known study to date on climate change and VLF, Stavros et al. (2014b) projected substantial increases in VLFs across the western US. However, their projections and modelling efforts focused on very coarse-scale management units that did not discriminate 
Table 1. Summary of the differences among the current paper and a sampling of similar studies that projected changes in future fire activity or fire danger indices under climate change across parts of the US

The table shows the temporal resolution (timescale), spatial resolution, period, geographic location, fire metric, vegetation types considered and main conclusion of each study. Only studies using a time-variant fire metric were considered. VLF, very large fire; ERC, energy release component; GACC, Geographic Area Coordination Center; KBDI, Keetch-Byram drought index; FFWI, Fosberg fire weather index

\begin{tabular}{|c|c|c|c|c|c|c|c|}
\hline Reference & Timescale & $\begin{array}{l}\text { Spatial } \\
\text { scale }\end{array}$ & Period & Location & $\begin{array}{l}\text { Fire metric or } \\
\text { fire proxy }\end{array}$ & Vegetation type & $\begin{array}{l}\text { Projected changes in fire activity or fire } \\
\text { proxy }\end{array}$ \\
\hline Brown et al. 2004 & Daily & $\sim 250 \mathrm{~km}$ & 2010-2089 & Western US & ERC & None & Increases in the number of high ERC days \\
\hline $\begin{array}{l}\text { Spracklen et al. } \\
2009\end{array}$ & Annual & $\sim 50 \mathrm{~km}$ & $2000-2050$ & Western US & Burned area & Bailey's ecoregions & $\begin{array}{l}\text { Increases of } 54 \% \text { in annual burned area by } \\
2050\end{array}$ \\
\hline Liu et al. 2010 & Monthly & $\sim 60 \mathrm{~km}$ & $2070-2100$ & Global scale & KBDI & None & $\begin{array}{l}\text { Increases in monthly KBDI across parts of } \\
\text { the world }\end{array}$ \\
\hline $\begin{array}{l}\text { Westerling et al. } \\
2011 a\end{array}$ & Monthly & $\sim 12 \mathrm{~km}$ & 2020-2085 & California & $\begin{array}{l}\text { Large fire and } \\
\text { burned area }\end{array}$ & $\begin{array}{l}\text { Vegetated } v s . \text { non- } \\
\text { vegetated lands }\end{array}$ & $\begin{array}{l}\text { Increases in burned area in Northern } \\
\text { California }\end{array}$ \\
\hline $\begin{array}{l}\text { Westerling et al. } \\
2011 b\end{array}$ & Monthly & $\sim 12 \mathrm{~km}$ & 1991-2100 & $\begin{array}{l}\text { Greater } \\
\text { Yellowstone }\end{array}$ & $\begin{array}{l}\text { Large fire and } \\
\text { burned area }\end{array}$ & Forested lands & Increases in burned area and fire frequency \\
\hline $\begin{array}{l}\text { Abatzoglou and } \\
\text { Kolden } 2011\end{array}$ & Daily & $\sim 8 \mathrm{~km}$ & 2046-2065 & Western US & ERC & None & Earlier onset and lengthening of fire season \\
\hline Liu et al. 2012 & Daily & $\sim 50 \mathrm{~km}$ & 2041-2070 & Conterminous US & KBDI \& FFWI & None & Increases in seasonal KBDI and FFWI \\
\hline Yue et al. 2013 & Monthly & $\sim 50 \mathrm{~km}$ & $2046-2065$ & Western US & Burned area & Bailey’s ecoregions & $\begin{array}{l}\text { Increases in monthly burned area and } \\
\text { expansion of fire season }\end{array}$ \\
\hline Luo et al. 2013 & Daily & $\sim 50 \mathrm{~km}$ & $2041-2070$ & Western US & Haines Index & None & $\begin{array}{l}\text { Increases in the consecutive number of high } \\
\text { daily Haines index }\end{array}$ \\
\hline Stavros et al. 2014 & Weekly & GACC & 2031-2060 & Western US & VLF occurrence & None & $\begin{array}{l}\text { Increases in VLF occurrence in climate- } \\
\text { limited ecosystems }\end{array}$ \\
\hline Current study & Weekly & $\sim 60 \mathrm{~km}$ & $2041-2070$ & Conterminous US & VLF occurrence & Omernik ecoregion & $\begin{array}{l}\text { Increases in VLF occurrence across } \\
\text { historically VLF prone regions }\end{array}$ \\
\hline
\end{tabular}

across ecoregions or include other portions of the US where VLFs have been observed in recent decades (Barbero et al. 2014b). Our study extends prior work by Stavros et al. (2014b) by resolving projected changes in VLF that account for varying climate-fire relationships facilitated through common vegetation assemblages at the ecoregion scale (e.g. Littell et al. 2009). Additionally, using the modelling framework proposed by Barbero et al. (2014a), we were able to capture intra-ecoregional variability in VLF at spatial $(\sim 60-\mathrm{km}$ grid) and temporal (weekly) scales that may be more relevant for informing management approaches to climate change than coarser scale approaches. Finally, our modelling approach includes projections of VLF encompassing fire-prone regions across the eastern half of the US where smoke from VLF affects large populations.

We examined changing opportunities for VLF ( $>5000$ ha) occurrence under climate change scenarios using empirical relationships between climatic factors and VLF occurrence developed by Barbero et al. (2014a). This empirical modelling effort cannot account for other factors that influence VLF such as changes in vegetation, land management and ignitions. However, by isolating projected changes in atmospheric drivers of VLFs, we sought to identify geographic hotspots of changing VLF occurrences. This guidance in turn may be useful in devising climate adaptation strategies for ecosystems and communities and help prioritise potential mitigation strategies.

\section{Data and methods}

Climate projections were obtained from 17 global climate models (GCMs) using historical forcing experiments from 1971 to 2000 and Representative Concentration Pathways 8.5 (RCP8.5) forcing experiments from 2041 to 2070 . The 17 GCMs comprised all CMIP5 models that contained daily output for both historical and RCP8.5 experiments for all variables required to compute fire danger measurements. We chose to focus on a single scenario (RCP8.5) as natural climate variability and inter-model variability are the dominant contributors to uncertainty in climate projections at such lead times and spatial scales (e.g. Hawkins and Sutton 2009). Coarse-scale GCM daily meteorological output was statistically downscaled using the Multivariate Adaptive Constructed Analogs method (Abatzoglou and Brown 2012) and the surface meteorological data of Abatzoglou (2013) to $1: 24^{\circ}$ resolution across the contiguous US. Following Barbero et al. (2014a), we calculated a set of predictors with established links to VLFs including meteorological variables (i.e. temperature, relative humidity, precipitation), the Palmer Drought Severity Index, annual climatic water deficit and fire danger indices from the National Fire Danger Rating System (Deeming et al. 1977), the Canadian Forest Fire Danger Rating System (Van Wagner 1987), and the Fosberg Fire Weather Index (Fosberg 1978). These variables reflect different timescales that are linked to VLF occurrence across ecoregions (table S1 from Barbero et al. 2014a). Climate-VLF relationships adhere to established interannual climate-fire relationships (e.g. Littell et al. 2009) in climatelimited and fuel-limited systems while also incorporating shorter timescales that are more directly linked to fire behaviour. Whereas all surface meteorological data were bias corrected through downscaling, a secondary bias correction was performed on all derived variables (e.g. fire danger indices, drought 
(a) Omernik ecoregions

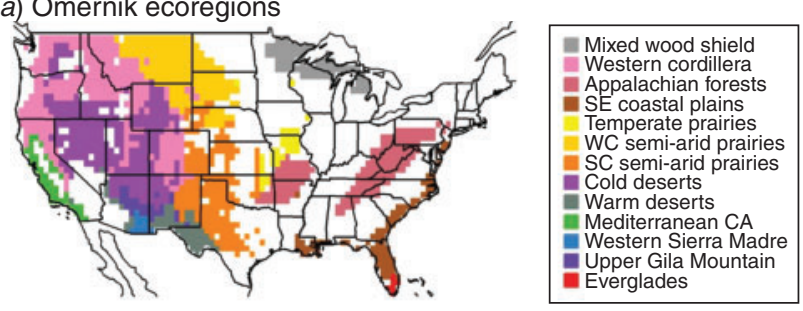

(b) Mean no. of VLF weeks expected (1971-2000)

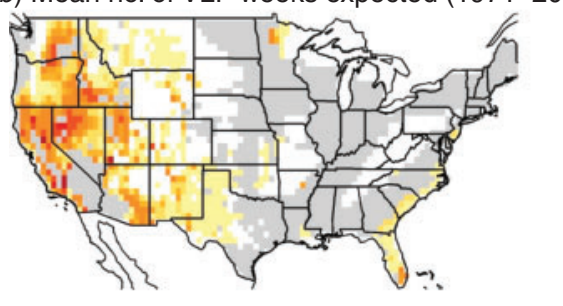

(c) Mean no. of VLF weeks expected (2041-2070)

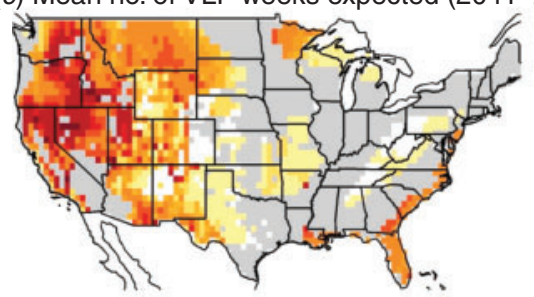

(d) Relative changes in \% (future-present)
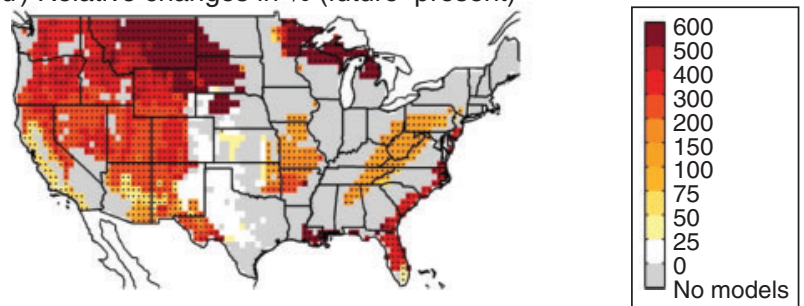

Fig. 1. a) Aggregated ecoregions at $\sim 60 \mathrm{~km}$ (full names of regions are shown in Table 1; abbreviations are defined in Table 2). Multi-model mean annual number of very large fire (VLF) weeks per surface uni $(\sim 60 \times 60 \mathrm{~km})$ for historic climate experiment $(b, 1971-2000)$ and mid21 st century climate experiment $(c, 2041-2070)$. Relative changes are shown in panel $d$ ). Stippling indicates pixels where the multi-model mean difference exceeded two standard deviations of 20th-century runs (i.e. spread among global climate models) and at least $90 \%$ of the models agree on the sign of change. Grey pixels indicate regions with no or insufficient number of VLF to build robust models.

metrics) following Stavros et al. (2014b). This bias correction forces data for the historical modelled period (1971-2000) to match the statistical moments of the observed distribution, and applies the same transformation to the future modelled period (2041-2070) thereby preserving differences between the two modelled datasets.

Barbero et al. (2014a) developed robust stepwise generalised linear models (GLMs) linking the occurrence of the top $10 \%$ of the largest historical VLFs ( $>5000$ ha) from 1984 to 2010 to atmospheric predictors at sub-ecoregion scales ( $\sim 60$-km grids) and weekly (6 day) timescales for 13 Omernik (Omernik 1987) Level II ecoregions of the US (Fig. 1a). Separate models were developed for each ecoregion given that climate-VLF relationships are mediated through vegetation, which when runs at the $60-\mathrm{km}$ scale allowing for spatial heterogeneity in predictors within an ecoregion (Table 2). A full description of model development and assessment is provided in Barbero et al. (2014a). Briefly, they used a logistic model with a logit link to model the probability of VLF week within each ecoregion at the voxel (defined here as a gridded value in a 3-dimensional space; i.e. time $\times$ space $)$ scale $(\sim 60 \mathrm{~km})$ using potential predictor variables. Interactive and non-linear terms were not included in the GLM. Predictor variables that did not exhibit significant relationships $(P<0.05)$ were discarded from stepwise model selection procedure. Model stability was examined through resampling approaches using a case-control design (Keating and Cherry 2004) that uses all VLF weeks and resampling with replacement of a subset of non-VLF weeks $(n=50000)$ drawn from the distribution of voxels within an ecoregion. They used the most frequent set of predictor variables from 1000 simulations for subsequent modelling. The area under the curve was used to evaluate model skill (reported in Table 2).

We project VLF probability at weekly timescales on $\sim 60$-km grids using downscaled GCM data aggregated to the aforementioned spatiotemporal resolution and the GLM equations from Barbero et al. (2014a). Specifically, we define VLF potential $(\mathrm{P})$ as the expected number of VLF $\left(10^{-4} \mathrm{~km}^{-2}\right)$ per week. This model is applied assuming that contemporary climate-fire relationships remain unchanged, thereby overlooking potential changes in vegetation. We avoided extrapolating our model outside the observed range of variability (e.g. Wotton et al. 2010; Moritz et al. 2012) by limiting variables to the range of historical variability for each ecoregion. Projected changes in $\mathrm{P}$ were examined across 17 GCMs at weekly and annual timescales between the mid-21st century (2041-2070) and late 20th century (1971-2000) runs. We focus on changes in the multimodel mean response (defined as the simple average of the 17 GCMs) and identify regions where the signal is robust, defined by where the multi-model mean difference between mid-21stcentury $\mathrm{P}$ and late-20th-century $\mathrm{P}$ exceeds two standard deviations of 20th-century runs (i.e. spread among models) and at least $90 \%$ of the models agree on the sign of change (IPCC 2013). We also quantify changes in $P$ for ecoregion across the 17 models to demonstrate the range and robustness of projected changes. Finally, we examined the length of the season during which atmospheric conditions are expected to be conducive to VLFs within each ecoregion. Although a universal definition of a VLF season is lacking, we considered the number of weeks during which at least one pixel within an ecoregion had probability above the historical 99th percentile (defined at the ecoregion level).

\section{Results}

Projected increases in P were modelled across much of the US, with the largest absolute increase in regions that observed numerous VLFs in recent decades including much of the intermountain West covering the Great Basin and Northern Rockies, as well as the Sierra Nevada and Klamath Mountains in Northern California (Fig. 1b, c). Increases were also projected across Northern Lakes and Forests, and in the Southern Coastal Plain, 
Table 2. Equations describing weekly VLF probabilities at $60 \mathrm{~km}$ for each ecoregion

The second column gives $\bar{\beta}$ parameters (see Barbero et al. $2014 a$ for further information on model development) for predictors that were selected in the stepwise regression. The third column indicates the mean area under the curve between simulated very large fire probabilities and observations from 1000 Monte Carlo simulations. Fourth and fifth columns indicate the multi-model mean of mean annual number of very large fires (VLFs) expected (VLF potential) per surface unit $\left(10^{4} \mathrm{~km}^{-2}\right)$ for the historical and future periods respectively. Predictors used in the equations are defined in Barbero et al. 2014a

\begin{tabular}{|c|c|c|c|c|}
\hline Ecoregions & $\exp (\bar{\beta}) / 1+\exp (\bar{\beta})$ & $\overline{A U C}$ & VLF P 1971-2000 & VLF P 2041-2070 \\
\hline Mixed Wood Shield & $\bar{\beta}=-15.24+B I \times 0.15+C W D \times 0.04$ & 0.95 & 0.14 & 0.80 \\
\hline Western Cordillera & $\bar{\beta}=-9.76+T E M P \times 0.22+E R C \times 0.05+P D S I \times(-0.25)$ & 0.95 & 0.81 & 3.31 \\
\hline Appalachian forest & $\bar{\beta}=4.08+R H \times(-0.17)+P D S I \times(-0.30)$ & 0.91 & 0.14 & 0.29 \\
\hline South-east (SE) Coastal Plains & $\bar{\beta}=-10.65+E R C \times 0.13+I S I \times 0.29$ & 0.89 & 0.38 & 1.03 \\
\hline Temperate prairies & $\bar{\beta}=5.12+R H \times(-0.21)$ & 0.95 & 0.24 & 0.41 \\
\hline West-central (WC) semiarid prairies & $\bar{\beta}=-12.22+E R C \times 0.09+I S I \times 0.20$ & 0.96 & 0.21 & 1.32 \\
\hline South-central (SC) semiarid prairies & $\bar{\beta}=-9.35+F F W I \times 0.23+P D S I_{-1} \times 0.23$ & 0.84 & 0.30 & 0.35 \\
\hline Cold deserts & $\bar{\beta}=-7.90+T E M P \times 0.26+E P \times(-0.47)+P D S I$ & 0.95 & 0.96 & 3.61 \\
\hline Warm deserts & $\begin{aligned} & \times 0.0916+I S I \times 0.14+P R C P_{J A S} \\
\bar{\beta}= & -9.79+I S I \times 0.22+P D S I \times 0.16\end{aligned}$ & 0.90 & 0.44 & 1.22 \\
\hline Mediterranean California (CA) & $\bar{\beta}=-4.20+T E M P \times 0.12+R H \times(-0.10)+F F W I \times 0.12$ & 0.90 & 1.87 & 3.03 \\
\hline Western Sierra Madre & $\bar{\beta}=-10.97+I S I \times 0.25+P D S I_{-1} \times 0.29$ & 0.95 & 1.59 & 3.61 \\
\hline Upper Gila Mountain & $\bar{\beta}=-11.28+E R C \times 0.08$ & 0.87 & 0.89 & 1.25 \\
\hline Everglades & $\bar{\beta}=-10.91+E R C \times 0.19$ & 0.84 & 1.44 & 1.87 \\
\hline
\end{tabular}

including much of Florida. These changes are consistent with an overall warming, more frequent heat waves (Diffenbaugh and Ashfaq 2010), and diminished soil moisture during the dry season (Orlowsky and Seneviratne 2012; IPCC 2013). The largest relative changes in $\mathrm{P}$ were found across the northern tier of the US (Fig. 1d); however, these changes result in moderate absolute increases in $\mathrm{P}$ in regions that had historically low $\mathrm{P}$.

Seasonal changes in $\mathrm{P}$ are illustrated for four ecoregions representative of changes modelled for other ecoregions (Fig. 2). Non-significant increases in annual $\mathrm{P}$ were projected in some non-forested ecoregions of the central US including the South-central semiarid prairies ecoregion (Fig. 2a). Respectively small and ambiguous changes in seasonal $\mathrm{P}$ were a function of muted and mixed changes in predictor variables historically important for VLFs in that region. Conversely, large increases in $\mathrm{P}$ were noted for the Western Cordillera ecoregion (Fig. $2 b$ ) due to increased temperature, and decreased relative humidity and precipitation during the summer that collectively lower fuel moisture and increase fire danger indices. Consequently, a significant and nearly symmetric increase in the $\mathrm{P}$ on either side of the historic seasonal maximum was modelled for the ecoregion that results in heightened $\mathrm{P}$ during the core of the fire season and an extension of the seasonal window conducive to VLFs. An earlier onset of the VLF season is projected across the south-western US including the Warm deserts ecoregion (Fig. 2c), corresponding to overall warming and a northward retraction of the winter storm track that results in decreased spring precipitation (e.g. Gao et al. 2014) and a resultant increase in the Initial Spread Index (ISI) - one of the leading predictor variables in that ecoregion. Conversely, models do not project any substantial change near the historical end of the VLF season associated with the arrival of monsoonal precipitation. Similarly, models project an earlier onset of the VLF season in the Everglades (Fig. $2 d$ ) in relation to anticipated warmer winter temperature and a return to normal conditions near the core of the historical VLF season.
Most ecoregions of the US not only experience higher mean annual P (Fig. $3 a$ ) but also a temporal expansion of extreme probability with climate change (Fig. $3 b$ ). The largest seasonal expansion of extreme probability is projected for the Western Cordillera, Mixed Wood Shield, Cold Deserts or South-east Coastal Plains ecoregions, where large increases in $\mathrm{P}$ are projected on either side of the seasonal maximum. However, most southern ecoregions (i.e. Everglades, Western Sierra Madre or Upper Gila Mountain) are likely to experience asymmetric changes in $\mathrm{P}$, featuring an earlier onset of atmospheric conditions favourable to VLF development but only small changes near the historical end of the VLF season. Substantial inter-model spread in projected changes in mean annual $\mathrm{P}$ and weeks of extreme probability are evident; however, nearly all model projections suggest increases above historical levels. One outlier model (GFDL-ESM2G) projects a decrease in VLF for the Mixed Wood Shield arising from a reduction in climatic water deficit and its incorporation in modelling VLF for that region.

\section{Conclusion and discussion}

Anthropogenic climate change is projected to increase VLF potential in the US through both an increase in frequency of conditions conducive to VLFs during the historical fire season and an extension of the seasonal window when fuels and weather support the spread of VLFs. The largest absolute changes are projected for regions across the western US where heightened VLF potential is the product of projected increases in fire danger and temperature, and decreased precipitation and relative humidity during the fire season (e.g. Abatzoglou and Kolden 2011; Liu et al. 2012; Luo et al. 2013; Stavros et al. 2014b). Projected changes in P by the mid-21st century follow a similar pattern to those modelled using observed changes in climate over the past three decades (Barbero et al. 2014a), although they are substantially larger in magnitude and suggest a continuation of more frequent VLF occurrences. 

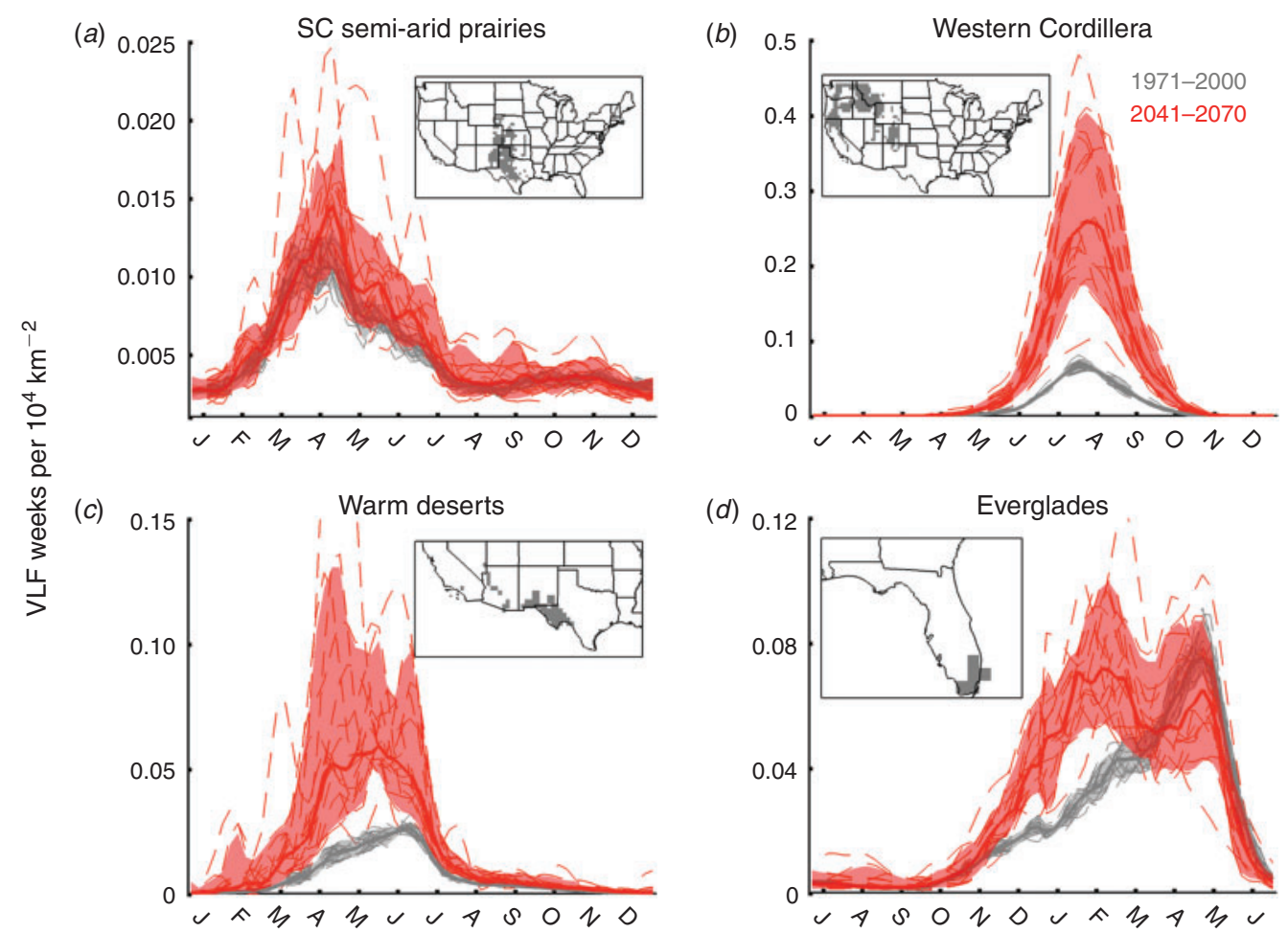

Fig. 2. Mean seasonal cycle of very large fire (VLF) potential (P) aggregated to Level II ecoregions from 1971 to 2000 (grey) and 2041 to 2070 (red). P is expressed as the mean number of VLF expected per surface unit $\left(10^{4} \mathrm{~km}^{-2}\right)$ per week. Individual models are shown by dashed curves and the solid bold lines indicate the multi-model mean. Grey and red envelopes indicate the $90 \%$ inter-model spread. The insert within each panel indicates the location of ecoregions. Notice that the last panel $(d)$ (Everglades) shows VLF P from July to June.

(a)

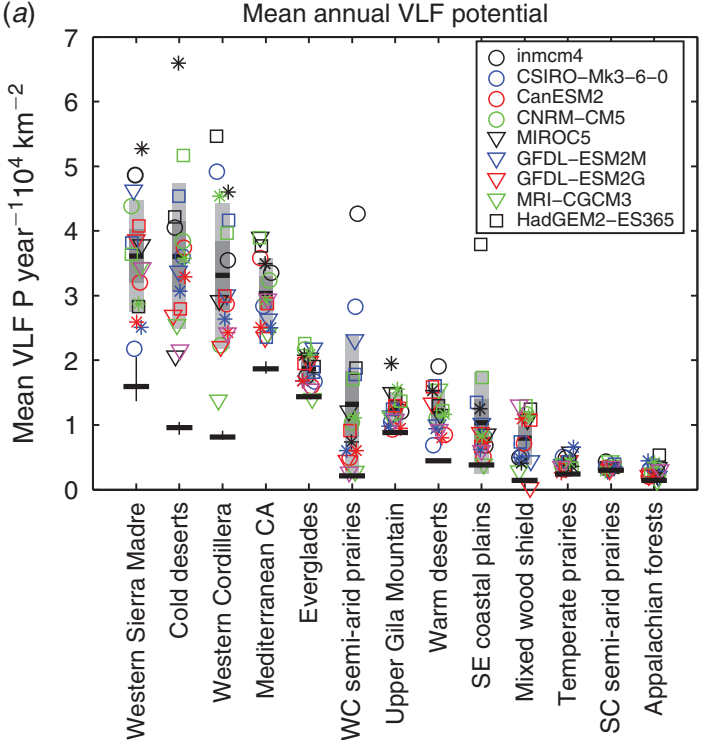

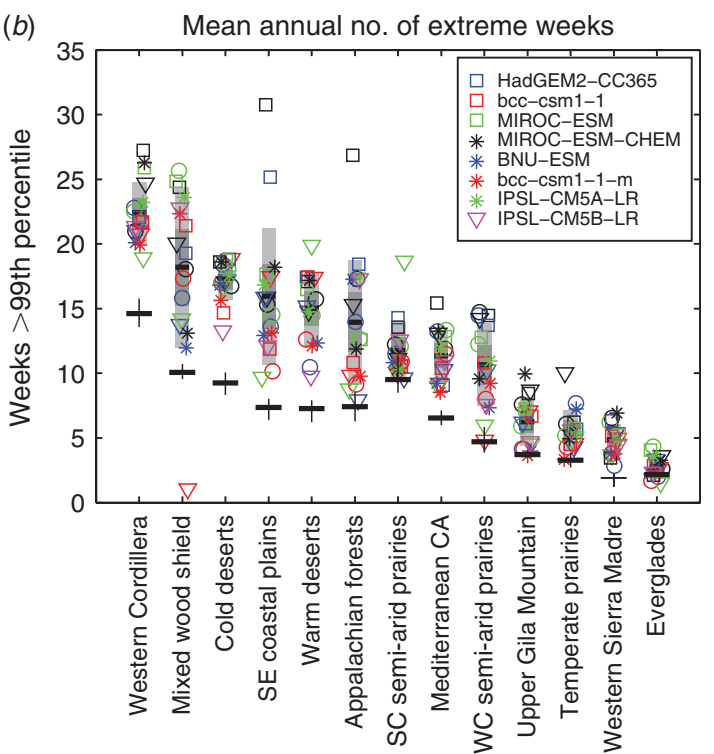

Fig. 3. a) Mean annual number of VLF weeks expected per surface unit $\left(10^{4} \mathrm{~km}^{-2}\right)$ within each ecoregion and $\left.b\right)$ the number of weeks during which at least one pixel within each ecoregion exceeded the historical 99th percentile. Vertical black lines indicate the historical range (1971-2000) across different global climate models and horizontal lines indicate the multi-model mean. Future projections for the mid-21st century (2041-2070) are depicted by symbols (as denoted by the legend split across the two plots), with the dark and light shading denoting one and two standard deviations from the multi-model mean respectively. The ranking of ecoregions is based on the multi-model mean of future runs (from largest to smallest values). 
Previous modelling studies project increased burned area under future climate across parts of the US using large-scale aggregated data on seasonal or monthly timescales (e.g. Spracklen et al. 2009; Yue et al. 2013). Our results provide an additional basis for such projections by showing that climate change may also enable increased opportunities for VLF occurrence that ultimately strongly contributes to total burned area. Our results also add to the much coarser scale VLF projections of Stavros et al. (2014b) by elucidating VLF projections at scales more relevant to wildfire and air quality management. Our results were in general agreement with Stavros et al. (2014b); however whereas they found small changes in VLF probabilities in Northern California and Western Great Basin, we show large increases within these regions in agreement with projected increases in burned area from Westerling et al. (2011a). Although the projected increases in P were smaller in absolute values in the eastern than in the western US, increased VLF occurrence may have broader effects on private property and air quality in the more densely populated regions of the eastern US than in the more sparsely populated western US.

Several uncertainties in such a modelling exercise may circumvent realised changes in VLFs. First, though models from Barbero et al. (2014a) exhibited strong skill, alternative models using different combinations of predictors may alter the magnitude of projected change depending on the sensitivity of such predictors to climate change. Second, models were developed using contemporary climate-fire relationships that are mediated through vegetation. Changes in vegetation distribution may alter fire regimes and subsequent climate-fire relationships used in modelling resulting in non-stationary fire-climate relationships (e.g. McKenzie et al. 2014; Higuera et al. 2015). For example, regions that experience frequent fire under climate change may have insufficient vegetation to carry VLF (e.g. Rocca et al. 2014), and shifts in forest composition and productivity in areas including the south-western US (e.g. Hurteau et al. 2014) may buffer modelled increases in VLFs. Conversely, changes in the distribution of invasive annual grasses conducive to VLFs may also shift in the future (Bradley 2009), altering model projections. Whereas dynamic global vegetation models designed to simulate vegetation dynamics (e.g. Lenihan et al. 2008) may provide a better understanding of the future complex relationships between vegetation, climate and fire, such process-based models provide fire estimates at coarse time steps and often prescribe fire return intervals or limit the spatial extent of fire a priori (McKenzie et al. 2014). Third, our modelling approach is considered conservative because we limited predictor variables to the historical range of variability and thus may underestimate future $\mathrm{P}$ in certain ecoregions where the historic range of variability will be exceeded. Finally, changes in ignition patterns and frequency resulting from changing distributions of lightning (Romps et al. 2014) and human factors may contribute to VLFs in ways other than modelled here.

Projected increases in VLF potential have important implications for terrestrial carbon emissions (Schultz et al. 2008; Prentice et al. 2011) and ecosystems (Keane et al. 2008), as well as communities, regional air quality and human health. Irrespective of the aforementioned caveats in modelling, the increased occurrence of VLFs will have significant effects on the effectiveness of traditional fire suppression activities. VLFs often require prolonged fire suppression commitments of resources, resulting in regional or national drawdown of resources that limit the capacity to fight fires in other regions, particularly when VLFs become the top national priority due to proximity to resources at risk or infrastructure. VLFs also tend to require much more complex, multi-agency management teams, fewer of which are available during the fire season. This complexity also can be associated with greater costs per unit area to fight the fire, as city and county agencies are often involved. The seasonal lengthening of conditions conducive to VLF will likely tax suppression-based activities, particularly during years of widespread and chronic VLF potential. Finally, an increase in the number of VLF could ultimately have negative effects on more holistic and science-driven fire management policies, such as reducing the amount of prescribed fire or fire used for resource benefits if managers fear that conditions will always be conducive to the development of VLFs. Recognising that potential for VLFs is likely to increase is key to developing proactive policies to combat these negative effects.

\section{Acknowledgements}

We are appreciative of constructive feedback from three anonymous reviewers and the associate editor in improving the quality of this manuscript. This research was funded by NOAA Regional Integrated Science Assessment program grant number: NA10OAR4310218) (JA) and the Joint Fire Science Program award number 11-1-7-4 (all authors).

\section{References}

Abatzoglou JT (2013) Development of gridded surface meteorological data for ecological applications and modeling. International Journal of Climatology 33, 121-131. doi:10.1002/JOC.3413

Abatzoglou JT, Brown TJ (2012) A comparison of statistical downscaling methods suited for wildfire applications. International Journal of Climatology 32, 772-780. doi:10.1002/JOC.2312

Abatzoglou JT, Kolden CA (2011) Climate change in Western US deserts: potential for increased wildfire and invasive annual grasses. Rangeland Ecology and Management 64, 471-478. doi:10.2111/REMD-09-00151.1

Barbero R, Abatzoglou JT, Steel EA (2014a) Modeling very large fire occurrences over the continental United States from weather and climate forcing. Environmental Research Letters 9. doi:10.1088/1748-9326/9/ $12 / 124009$

Barbero R, Abatzoglou JT, Kolden C, Hegewisch K, Larkin NK, Podschwit $H$ (2014b) Multi-scalar influence of weather and climate on very large fires in the Eastern United States. International Journal of Climatology. doi:10.1002/JOC.4090

Bradley BA (2009) Regional analysis of the impacts of climate change on cheatgrass invasion shows potential risk and opportunity. Global Change Biology 15, 196-208. doi:10.1111/J.1365-2486.2008.01709.X

Brown TJ, Hall BL, Westerling AL (2004) The impact of twenty-first century climate change on wildland fire danger in the western United States: an application perspective. Climatic Change 62, 365-388. doi:10.1023/B:CLIM.0000013680.07783.DE

Deeming JE, Burgan RE, Cohen JD (1977) The National Fire Danger Rating System - 1978. USDA Forest Service, Intermountain Forest and Range Experiment Station. General Technical Report, INT-39 (Ogden, UT).

Dennison PE, Brewer SC, Arnold JD, Moritz MA (2014) Large wildfire trends in the western United States, 1984-2011. Geophysical Research Letters 41, 2928-2933. doi:10.1002/2014GL059576

Diffenbaugh NS, Ashfaq M (2010) Intensification of hot extremes in the United States. Geophysical Research Letters 37, L15701. doi:10.1029/ 2010GL043888 
Flannigan MD, Krawchuk MA, de Groot WJ, Wotton BM, Gowman LM (2009) Implications of changing climate for global wildland fire. International Journal of Wildland Fire 18, 483-507. doi:10.1071/ WF08187

Fosberg MA (1978) Weather in wildland fire management: the fire weather index. In 'Proceedings of the conference on Sierra Nevada meteorology', 19-21 June 1978, South Lake Tahoe, NV. pp. 1-4. (American Meteorological Society, Boston, MA)

Gao Y, Leung LR, Lu J, Liu Y, Huang M, Qian Y (2014) Robust spring drying in the southwestern US and seasonal migration of wet/dry patterns in a warmer climate. Geophysical Research Letters 41, doi:10.1002/2014GL059562

Gillett NP, Weaver AJ, Zwiers FW, Flannigan MD (2004) Detecting the effect of climate change on Canadian forest fires. Geophysical Research Letters 31, L18211. doi:10.1029/2004GL020876

Hawkins ED, Sutton R (2009) The potential to narrow uncertainty in regional climate predictions. Bulletin of the American Meteorological Society 90, 1095-1107. doi:10.1175/2009BAMS2607.1

Higuera PE, Abatzoglou JT, Littell JS, Morgan P (2015) The changing strength and nature of fire-climate relationships in the Northern Rocky Mountains, U.S.A., 1902-2008. PLoS ONE 10, e0127563. doi:10.1371/ JOURNAL.PONE.0127563

Hurteau MD, Bradford JB, Fulé PZ, Taylor AH, Martin KL (2014) Climate change, fire management, and ecological services in the southwestern US. Forest Ecology and Management 327, 280-289. doi:10.1016/ J.FORECO.2013.08.007

IPCC 2013: Climate change 2013: The physical science basis. Contribution of Working Group I to the Fifth assessment report of the Intergovernmental Panel on Climate Change (Eds TF Stocker, D Qin, G-K Plattner, M Tignor, SK Allen, J Boschung, A Nauels, Y Xia, V Bex, PM Midgley) (Cambridge University Press: Cambridge, UK and New York, NY). doi:10.1017/CBO9781107415324.. doi:10.1017/CBO9781107415324

Johnston FH, Henderson SB, Chen Y, Randerson JT, Marlier M, Defries RS, Kinney P, Bowman DMJS, Brauer M (2012) Estimated global mortality attributable to smoke from landscape fires. Environmental Health Perspectives 120, 695-701. doi:10.1289/EHP.1104422

Keane RE, Agee JK, Fulé P, Keeley JE, Key C, Kitchen SG, Miller R, Schulte LA (2008) Ecological effects of large fires on US landscapes: benefit or catastrophe? International Journal of Wildland Fire 17, 696-712. doi:10.1071/WF07148

Keating KA, Cherry S (2004) Use and interpretation of logistic regression in habitat selection studies. The Journal of Wildlife Management $\mathbf{6 8}$ 774-789. doi:10.2193/0022-541X(2004)068[0774:UAIOLR]2.0.CO;2

Lenihan JM, Bachelet D, Neilson RP, Drapek R (2008) Response of vegetation distribution, ecosystem productivity, and fire to climate change scenarios for California. Climatic Change 87(Suppl.), 215-230. doi:10.1007/S10584-007-9362-0

Littell JS, McKenzie D, Peterson DL, Westerling AL (2009) Climate and wildfire area burned in western US ecoprovinces, 1916-2003. Ecological Applications 19, 1003-1021. doi:10.1890/07-1183.1

Liu YQ, Stanturf JA, Goodrick SL (2010) Trends in global wildfire potential in a changing climate. Forest Ecology and Management 259, 685-697. doi:10.1016/J.FORECO.2009.09.002

Liu YQ, Goodrick SL, Stanturf JA (2012) Future US wildfire potential trends projected using a dynamically downscaled climate change scenario. Forest Ecology and Management. doi:10.1016/J.FORECO. 2012.06.049

Luo L, Tang Y, Zhong S, Bian X, Heilman WE (2013) Will future climate favor more erratic wildfires in the western United States? Journal of Applied Meteorology and Climatology 52, 2410-2417. doi:10.1175/ JAMC-D-12-0317.1

Marlon JR, Bartlein PJ, Gavin DG, Long CJ, Anderson RS, Briles CE, Brown KJ, Colombaroli D, Hallett DJ, Power MJ, Scharf EA, Walsh MK (2012) Long-term perspective on wildfires in the western USA.
Proceedings of the National Academy of Sciences of the United States of America 109, E535-E543. doi:10.1073/PNAS.1112839109

McKenzie D, Shankar U, Keane RE, Stavros EN, Heilman WE, Fox DG, Riebau AC (2014) Smoke consequences of new wildfire regimes driven by climate change. Earth's Future 2, 35-59. doi:10.1002/ 2013EF000180

Moritz MA, Parisien MA, Batllori E, Krawchuk MA, Van Dorn J, Ganz DJ, Hayhoe K (2012) Climate change and disruptions to global fire activity. Ecosphere 3. doi:10.1890/ES11-00345.1

Omernik JM (1987) Ecoregions of the conterminous United States (map supplement). Annals of the Association of American Geographers $\mathbf{7 7}$ 118-125. Available at http://dusk2.geo.orst.edu/prosem/PDFs/lozano_ Ecoregions.pdf [Verified 18 June 2015]

Orlowsky B, Seneviratne SI (2012) Global changes in extreme events: regional and seasonal dimension. Climatic Change 110(3-4), 669-696. doi:10.1007/S10584-011-0122-9

Prentice IC, Kelley DI, Foster PN, Friedlingstein P, Harrison SP, Bartlein PJ (2011) Modeling fire and the terrestrial carbon balance. Global Biogeochemical Cycles 25, GB3005. doi:10.1029/2010GB003906

Rhoades CC, Entwistle D, Butler D (2011) The influence of wildfire extent and severity on streamwater chemistry, sediment and temperature following the Hayman Fire, Colorado. International Journal of Wildland Fire 20(3), 430-442. doi:10.1071/WF09086

Riley KL, Abatzoglou JT, Grenfell IC, Klene AE, Heinsch FA (2013) The relationship of large fire occurrence with drought and fire danger indices in the western USA, 1984-2008: the role of temporal scale. International Journal of Wildland Fire. doi:10.1071/WF12149

Rocca ME, Brown PM, MacDonald LH, Carrico CM (2014) Climate change impacts on fire regimes and key ecosystem services in Rocky Mountain forests. Forest Ecology and Management. doi:10.1016/ J.FORECO.2014.04.005

Romps DM, Seeley JT, Vollaro D, Molinari J (2014) Projected increase in lightning strikes in the United States due to global warming. Science 346(6211), 851-854. doi:10.1126/SCIENCE.1259100

Schultz MG, Heil A, Hoelzemann JJ, Spessa A, Thonicke K, Goldammer JG, Held AC, Pereira JMC, van het Bolscher M (2008) Global wildland fire emissions from 1960 to 2000. Global Biogeochemical Cycles 22, GB2002. doi:10.1029/2007GB003031

Spracklen DV, Mickley LJ, Logan JA, Hudman RC, Yevich R, Flannigan MD, Westerling AL (2009) Impacts of climate change from 2000 to 2050 on wildfire activity and carbonaceous aerosol concentrations in the western United States. Journal of Geophysical Research 114, D20301. doi:10.1029/2008JD010966

Stavros EN, Abatzoglou JT, Larkin NK, McKenzie D, Steel EA (2014a) Climate and very large wildland fires in the contiguous western USA International Journal of Wildland Fire 23(7), 899-914. doi:10.1071/ WF13169

Stavros EN, Abatzoglou JT, McKenzie D, Larkin NK (2014b) Regional projections of the likelihood of very large wildland fires under a changing climate in the contiguous Western United States. Climatic Change 126(3-4), 455-468. doi:10.1007/S10584-014-1229-6

Stocks BJ, Fosberg MA, Lynham TJ, Mearns L, Wotton BM, Yang Q, Jin JZ, Lawrence K, Hartley GR, Mason JA, McKenney DW (1998) Climate change and forest fire potential in Russian and Canadian boreal forests. Climatic Change 38(1), 1-13. doi:10.1023/A:1005306001055

Strauss D, Bednar L, Mees R (1989) Do one percent of forest fires cause ninety-nine percent of the damage? Forest Science 35, 319-328.

Van Wagner CE (1987) Development and structure of the Canadian Forest Fire Weather Index System. Canadian Forestry Service, Forestry Technical Report 35. (Ottawa, ON).

Westerling AL, Brown TJ, Gershunov A, Cayan DR, Dettinger MD (2003) Climate and wildfire in the Western United States. Bulletin of the American Meteorological Society 84(5), 595-604. doi:10.1175/ BAMS-84-5-595 
Westerling AL, Hidalgo HG, Cayan DR, Swetnam TW (2006) Warming and earlier spring increase western US forest wildfire activity. Science 313, 940-943. doi:10.1126/SCIENCE.1128834

Westerling AL, Bryant BP, Preisler HK, Holmes TP, Hidalgo H, Das T, Shrestha S (2011a) Climatic change and growth scenarios for California wildfire. Climatic Change 109(s1), 445-463. doi:10.1007/S10584-0110329-9

Westerling AL, Turner MG, Smithwick EAH, Romme WH, Ryan MG (2011b) Continued warming could transform greater Yellowstone fire regimes by mid-21st century. Proceedings of the National Academy of Sciences of the United States of America 108(32), 13 165-13 170. doi:10.1073/PNAS.1110199108

Wotton BM, Nock CA, Flannigan MD (2010) Forest fire occurrence and climate change in Canada. International Journal of Wildland Fire 19, 253-271. doi:10.1071/WF09002

Yue X, Mickley LJ, Logan JA, Kaplan JO (2013) Ensemble projections of wildfire activity and carbonaceous aerosol concentrations over the western United States in the mid-21st century. Atmospheric Environment 77, 767-780. doi:10.1016/J.ATMOSENV.2013.06.003 